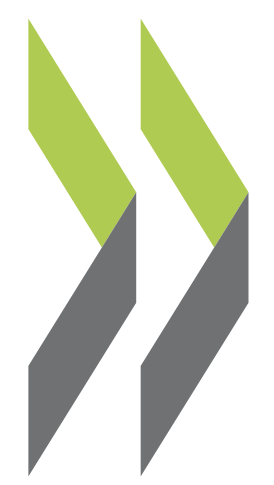

PEB Exchange, Programme on Educational Building 1998/07

\title{
Architectural Competition for a Secondary School in Switzerland
}

\author{
Eric Biéler,
}

\section{Michael Hacker}




\section{ARCHITECTU RAL COMPETITION FOR A SECONDARY SCHO O L IN SWITZERLAND}

\section{Introduction}

The provision of new schools in established urban areas poses specific design challenges that are not common to schools on green field sites: the need to build to high densities to make the best possible use of scarce and expensive land; the desire to conserve the historic urban heritage; the need to enhance the quality of the urban environment; the obligations to respect the rights of adjoining properties to light, access and privacy; and the requirements to protect the users from the noise and pollution of urban transport. Responding to such constraints, in addition to satisfying the exacting requirements of current educational programmes, requires imagination and design skills of the highest order.

Proposals to build a new secondary school close to the busy commercial centre of the city of Geneva posed just such a challenge and to meet it the authorities organised a two stage architectural competition.

The brief for the new school embodies many issues that are germane to the PEB programme of work; demographic change and the need to provide for a rise in demand for student places; the greening of the school site and maximising the potential of school grounds for education and recreation; providing for the community use of school facilities outside of school hours; meeting changes in educational practice and information technology by providing buildings which are flexible and adaptable; and providing a supportive and healthy environment that is economical to run and easy to maintain.

In Summer 1997 an architectural competition was launched in Geneva for a junior secondary school (750 pupils aged 12 to 15), and PEB was indirectly represented on the panel of judges. In the winning design, educational needs have clearly not been compromised by architectural considerations.
In quantitative terms, local demographic trends have made it necessary to plan for an additional school by the year 2003. The number of students in junior secondary education in Geneva reached 10700 at the beginning of the 1991/92 school year. It remained stable until the year 1997 which saw an increase of about 200 students. It is estimated that enrolment will reach 12000 in 2002 and 13000 in 2005.

The 16000 square-metre site is situated near Geneva's main-line railway station and the city centre, on the edge of parkland surrounded by dense housing. Adjoining the site are a massive postal sorting-office within the perimeter of the station, some old blocks of apartments for rent, an imposing turn-of-the-century primary school, and the parkland mentioned above. This is an island of green in a highly urbanised environment and includes some magnificent, protected trees and a large house dating back to 1755 , but sadly in need of repair. On the edge of the park are other buildings, all in public use, namely a church, a community centre and a restaurant.

\section{Junior secondary education in Geneva}

Junior secondary education (known as the Cycle d'orientation) follows the sixth year of primary schooling and includes the last three years of compulsory education. Its purpose is to prepare virtually all 12 - to 15 -year-olds for entrance to vocational or academic courses, recommending them for one or the other according to their interests and skills. Junior secondary pupils do not all follow the same curriculum, but may change stream in the course of those three years.

\section{Traditional junior-secondary school design}

The 14 junior-secondary school buildings put up in Geneva from 1962 to 1975 are confined to the basic facilities required for administrative and educational purposes. Rooms open off long, narrow corridors in one or two blocks of three to five storeys. The designs lack imagination and have no "pupil areas" other than classrooms, which are kept locked between lessons. This is the kind of design that is acceptable for a school teaching a rigid curriculum, on a strict timetable, to pupils who will spend the whole year in their designated groups. 


\section{Educational trends}

However, a number of constraints have prompted a shift in this traditional teaching environment. Nowadays, school is the first structure called upon to compensate for the decline in the support shown for young people by their families. Rapid economic change is also forcing the education system to look again at how it prepares young people for working life. And the development of information and communication technology (ICT) is contributing to an educational shift towards greater personal initiative and individual creativity.

On a more practical level, secondary education can no longer be confined to a series of lectures, and adolescents are no longer just one of a crowd in class, but increasingly people in their own right, following their course.

In light of this, new educational goals were drawn up for the competition:

- to foster the development of new teaching practices, namely interdisciplinarity, group work and teamwork;

10 - to incorporate information and communication technologies;

- to encourage pupils to socialise (within the school community) and take part in the life of the school;

to develop the idea of an educational community (with no strictly compartmentalised functionș:

\section{Prior to the competition}

To translate these goals into a programme of -specifications for the buildings and-other areas,

- in a the a thorities called in a sociologist and an H If I architect from France, both of whon had already worked on a similar pitoeprojectror a boarding schoo commissioned by the Frenchinistry of (1): Algric ilture. They began by talking to each user category (management, administrat ve/technical staff, teachers and pupils) about their future needs, particularly regarding soci 1 life within the school. Then they checked their initial findings against ar survey of users in similar institutions before holding discussions with users, teach ers and administrative officials, with the orocess eventually producing a settof specifica tons for the competition.
The following principles were identified regarding the layout and general organisation of the future school:

1.The need for diversification as regards volume and space, avoiding pupils being crow ded in stairways and corridors and encouraging a variety of connecting areas.

\section{Activities to be grouped into well-defined areas:}

Area 1: language, history and geography teaching; Area 2: mathematics and science teaching;

Area 3: creative activities;

Area 4: sports lessons;

Area 5: media library, computing;

Area 6: hall and reception areas;

Area 7: management, administration;

Area 8: cafeteria, "noisy" recreational activities (game room: table tennis, table football, etc.);

Area 9: "quiet" activities (reading, resting, private study);

Area 10: outdoor facilities.

3. The creation of open social and study areas for private study, group work, or spontaneous recreation and socialising.

\section{O rganisation of the architectural competition}

For a variety of local reasons, Geneva's political authorities wanted outside architects to take part in the competition. O $n$ the panel, the two foreign judges were Mrs. A. Castro-Rial Garrone, head of architecture and building for the city of $\mathrm{Ma}$ drid and former Spanish delegate to PEB, and M r. M. Hacker, from the U nited Kingdom, former Chairman of PEB. The panel also included two Swiss and eight Genevan architects, a historian, a member of the government, four civil servants and (only) one education official.

O ne hundred twenty-one architectural firms (eight of them from EC member countries) took partin the first round of the competition, which was yudgedion how well the school was sited and designed. Seventeen projects were selected for the second round, on the basis of additional functional and organisational criteria as well as architectural and economic factors (construction costs and energy-related operating costs). It is interestingto note that the winning project is the one that comes closest to meeting current educational concerns and likely developments in educational practice in the not-too-distant future. 


\section{Panel's verdict}

Although excessively simple in terms of volume, the design clearly fits well into the natural and built environment. It forms a bridging volume between the central post office and the Cropettes primary school, while at the same time respecting the existing buildings. U nfortunately it is rather too close to the existing eighteenth century building, the "Villa Roux".

Entrances from the three adjacent roads are clearly defined and the very wide, transversal opening reaching up two storeys highlights the pedestrian path leading from the parks in the west to Rue Montbrillant in the east. The wide porch matches the scale of the building and the project as a whole. However, service entrances are inadequate. Most of the existing parkland within the perimeter has been conserved, as have the mature trees.

The fact that all the outdoor sports areas have been grouped on the roof offers the advantage of allowing all the remaining space to be used for pathways, greenery and recreation areas. However, solutions will have to be found regarding access to these sports areas.

The highly compact architecture includes a wide variety of indoor spaces which, in particular, liven up the layout of teaching areas and other parts of the building. The structure is coherently expressed, but includes some very large spans ( $15 \mathrm{~m}$ and $30 \mathrm{~m}$ ) that might be expensive to build. The possibility of reducing most of these spans needs to be examined. As recommended by the judges at the close of the first round of the competition, similar disciplines have been grouped on the same floors.

The teaching areas opening out onto the patios are well chosen, in terms of the degree of natural light. The design lends itself to flexibility of use, from the point of view of adapting to changes in educational methods.

Areas open to the public outside of school hours (gymnasium, auditorium, media library, etc.) are grouped to the north. Entrances are clearly defined and can be made independent. Access to the various gymnasia is inadequate.

Given the relatively high (gross) floor area, the project is quite economical, with construction costs

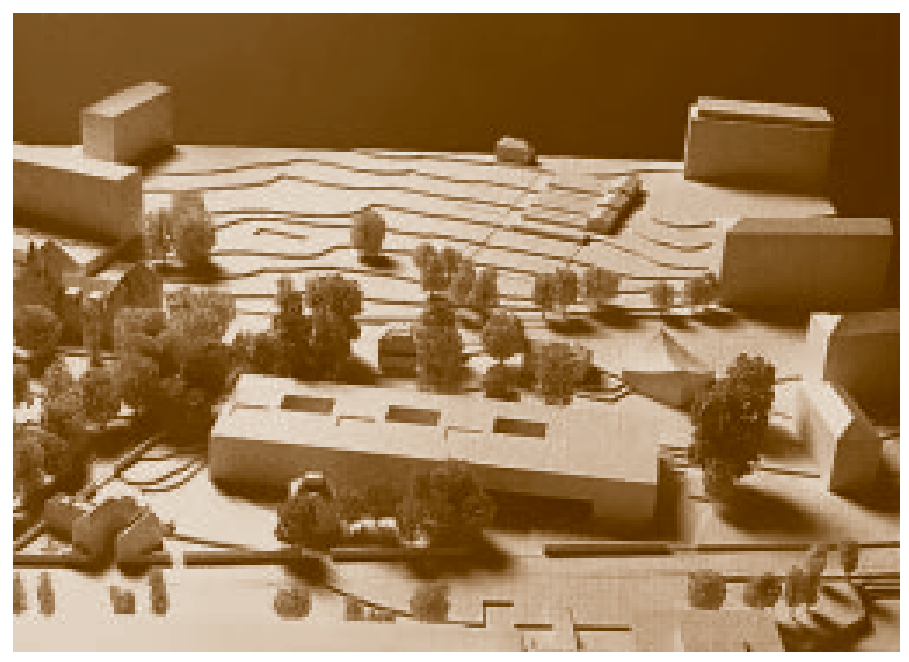

at around the current average. The "loop" layout provides scope for substantial savings on mechanical and electrical services. With its compact design, the building has an excellent energy-efficiency rating.

This simple, traditional building project is suitable for multi-stage construction.

\section{Construction}

A commission is currently working on a final, detailed version of the successful design project. The commission brings together the architects, the owner (Department of Land-U se Planning, Public Works and Housing) and above all (at last), representatives of future users, i.e. teachers and technical officials from the department of public education. In close collaboration with the user groups for each building in the programme, the functional characteristics of each part of the premises are being defined in detail, in conjunction with the building plans and detailed estimates of the cost of the project. Provided that the Genevan authorities vote the necessary funds and that the current tenants (self-employed craftsmen) have left by next spring, building work should start at the beginning of the year 2000 and be completed in time for the school to open in September 2002.

This article was contributed by Eric Biéler, architect at the Geneva Department of Public Education and member of the PEB Steering Committee, and Michael Hacker, former Chair of the PEB Steering Committee. For further information, contact Mr. Biéler: Fax: 412231042 90, E-mail: bieler-e@dip.etat-ge.ch. 